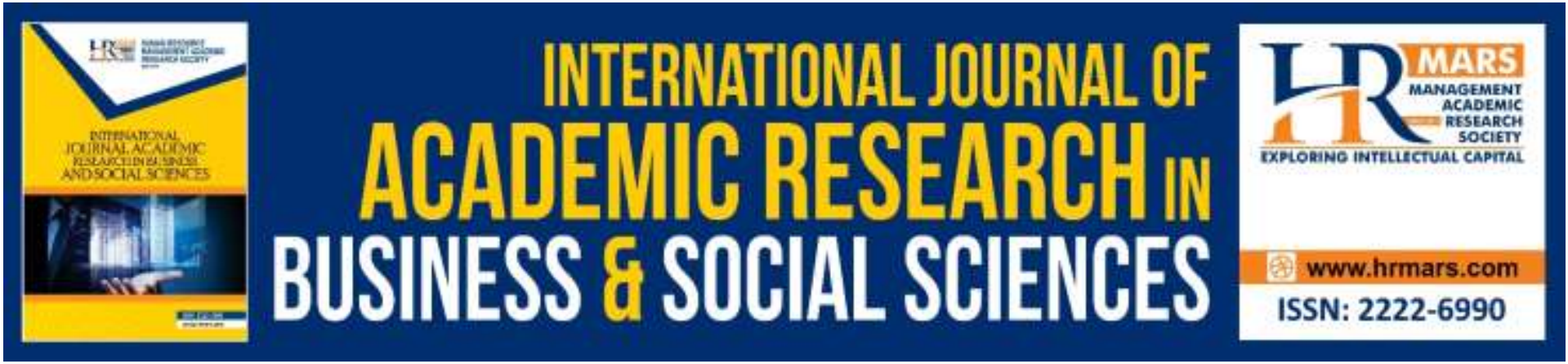

\title{
The Fallacy of Consistency in Assessing Permanent Future Loss in a Personal Injury Claim: The Malaysian Practice Dilemma
}

Mohd Fuad Husaini

To Link this Article: http://dx.doi.org/10.6007/IJARBSS/v9-i7/6163

DOI: $10.6007 /$ IJARBSS/v9-i7/6163

Received: 25 May 2019, Revised: 27 June 2019, Accepted: 03 July 2019

Published Online: 25 July 2019

In-Text Citation: (Husaini, 2019)

To Cite this Article: Husaini, M. F. (2019). The Fallacy of Consistency in Assessing Permanent Future Loss in a Personal Injury Claim: The Malaysian Practice Dilemma. International Journal of Academic Research in Business and Social Sciences, 9(7), 714-725.

Copyright: (C) 2019 The Author(s)

Published by Human Resource Management Academic Research Society (www.hrmars.com)

This article is published under the Creative Commons Attribution (CC BY 4.0) license. Anyone may reproduce, distribute, translate and create derivative works of this article (for both commercial and non-commercial purposes), subject to full attribution to the original publication and authors. The full terms of this license may be seen at: http://creativecommons.org/licences/by/4.0/legalcode

Vol. 9, No. 7, 2019, Pg. 714 - 725

http://hrmars.com/index.php/pages/detail/IJARBSS

JOURNAL HOMEPAGE

Full Terms \& Conditions of access and use can be found at http://hrmars.com/index.php/pages/detail/publication-ethics 


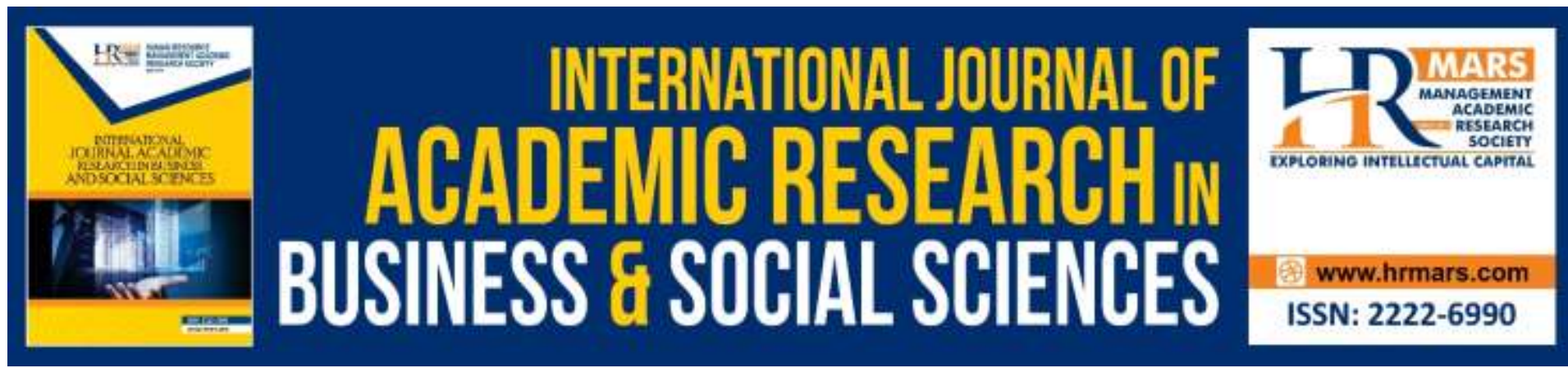

\title{
The Fallacy of Consistency in Assessing Permanent Future Loss in a Personal Injury Claim: The Malaysian Practice Dilemma
}

\author{
Mohd Fuad Husaini \\ Faculty of Law and International Relations, University Sultan Zainal Abidin (UniSZA), \\ Malaysia \\ Email: mohdfuad@unisza.edu.my
}

\begin{abstract}
Damages under the law of tort as applied in Malaysia is based on corrective compensation scheme under the principle of restitutio in integrum. The principle lays that the purpose of damage is to restore the plaintiff to its original position if the tort had not been committed. Whilst this principle lays no apparent problem in its implementation; however, in the realm of calculating damages for future losses, the Courts have adopted an assortment of calculations and assessment. The dependency and future loss of earnings are regulated by the statutory provisions in the form of Section 7(3)(c) and 28A(2)(c) of the Civil Law Act, 1956 respectively. However, other future losses such as permanent future nursing care have been left in vain to the extent that the Courts seem to recognize 5 distinct multipliers for calculating permanent future nursing care, which bears contrasting results. Even the current Civil Law (Amendment) Act, 2019 has still not addressed this issue. The need for a consistent methodology is crucial as justice demands that a similar standard is applied to all parties in order to achieve a consistent outcome for the like cases. The law cannot treat like cases with different outcome. This paper highlights the fallacy that there is a consistent standard in assessing continuing and permanent future loss in a personal injury claim, especially with regards to nursing care and medical expenses; which in turn results in contrasting outcomes.
\end{abstract}

Keywords: Personal Injury, Damages, Future Nursing Care.

\section{Introduction}

Damages are a sum of money given to the plaintiff as compensation for loss or harm caused by the defendant (Ahangar, 2009). To compensate a person is to make good an undesirable aspect of their circumstances or situation in life, which falls below some pre-determined benchmark of acceptability. Compensation for personal injury in Malaysia is based on the principle of restitutio in integrum, i.e. to restore the 
plaintiff to the position he or she would have been in if the relevant tort had not been committed.

Tort law compensates not only for financial changes in a person's life but also for adversities, which cannot, in any meaningful sense, be measured in money (Cane, 2013). An example is the statutory bereavement of loved ones wherein a fixed sum of RM10,000 is given for the demise of spouse or off-springs (as provided under Section 7(3A) and 3(b) of the Civil Law Act, 1956), which is difficult to think of anything that would count as a substitute. It should be noted however that the bereavement sum of RM 10,000 has now been increased to RM 30,000 vide Civil Law (Amendment) Act, 2019. This amendment Act was gazetted on 31 May 2019 but is yet to come into force.

In tort, the highest limit of damages is the whole extent of loss sustained by the plaintiff (McConnel v. Wright, 1903). Thus, damages should not exceed the "loss", nor should it be less than the "loss", which makes quantifying the damages an arduous process capped guided by judicial precedent and discretion.

\section{Predicting the Future}

Damages for personal injury and death typically take the form of a lump sum. The award or settlement is made once and for all. Except in rare cases, there is no possibility of increasing it or decreasing it later because of changes in the claimant's situation (Cane, 2013).

In a hypothetical scenario based on actual facts of a case (John s/o Netchumayah $v$. Marimuthu, 1985), a plaintiff, who was 30 years old, was involved in an accident and suffered a spinal injury which left him paralysed below the neck. Twenty-one months after the accident (at the date of trial), the plaintiff is still hospitalised and paralyzed. From the medical documents, it is plainly clear that he will never be able to walk again and is greatly dependent on others for his living vicissitudes. The plaintiff was formerly a cinema operator earning approximately RM 580 a month, including overtime. There are also costs of nursing care at RM 200 a month, and the medical specialist indicated that he would never recover from the paralysis and would require permanent future nursing care.

From the above factual circumstances, for his injuries and residuals sufferings, the quantifiable damages are typically based on the precedents of authorities. All other future losses and expenses would also usually fall within the category of general damages, such as future loss of earnings, costs of surgery, medications and nursing care. For the loss of earnings, the provision of a fixed multiplier is clearly stipulated under section $28 \mathrm{~A}(2)$ (d) of the Civil Law Act, 1956, though the Court should segregate the multiplier into pre-trial (actual losses) and post-trial (future losses). Pre-trial damage falls under the category of special damages. Since it is special damage, it would also carry a different proportion of interests commencing from the date of accident ("date of loss") as compared to general damages, which commence from the date of service of the writ. The statutorily fixed multiplier placed a cap of the age of 55 years; which is now been increased to 60 years vide the Civil Law (Amendment) 
Act, 2019, as the limit to be able to claim for future loss of earnings with a two-tier level of assessment; persons below the age of 30 and those who are between 30 and 55. The court's task is then to determine the multiplicand based on the factual evidence at hand. Thus, if the court accepts RM 580 as the multiplicand, the calculation for the damages for loss of earnings would be based on 16 years multiplier.

However, for other permanent future loss such as future nursing care, the statute is silent on the multiplier, and the court is left to rely on precedent authorities to determine the multiplier. Even the recently gazetted Civil Law (Amendment) Act, 2019 has not laid down any guide for the assessment of this kind of permanent future loss. The problem of assessing this type of permanent future loss is compounded further when precedent authorities do not seem to be in consensus on a single approach. While the multiplicand on another hand would be based on the factual evidence of each case, the multiplier is an exercise of predicting the future. Without a prescribed or a reliable method to calculate multiplier for future loss of nursing care and medication for cases where the prognosis is permanent nursing care for the rest of the person's life; there seems to be a multitude of methods in determining the multiplier that leads to contrasting results. The current situation cannot be allowed to remain. The need for a consistent methodology is crucial as justice demands that a similar standard is applied to all parties in order to achieve a consistent outcome for the like cases. The law cannot treat like cases with different outcome.

The complexity of multiplier in this sense will only arise if there is evidence of permanent future nursing care required for permanent and totally disabled persons, as in the cases of paralysed and comatose claimants. If the medical experts only prescribe a specific duration for nursing care, the problem of computation would not arise as the time prescription would be imputed in assessing the damages without having to consider the full multiplier.

\section{Future Nursing Care}

Nursing care in tortuous actions occurs where the victim (plaintiff) is unable to maintain and care for himself as a result of an accident or unfortunate turn of an event, and he seeks for monetary compensation or damages in order for him to seek for care, specialized or otherwise due to his injuries and residual disabilities.

In contrast to the loss of future dependency and loss of future earnings, the assessment for permanent future nursing care/medical expenses has been left to fend itself by the legislators; allowing discretion of the Courts to apply an assortment of methods to calculate the years' purchase for loss of future permanent nursing care costs. There are 5 different approaches which have been used by the Malaysian Courts in determining the multiplier for this kind of permanent future loss. The 5 approaches are: -

(a) Applying a direct multiplier of 16 years, following Marappan \& Anor v. Siti Rahmah bte Ibrahim (1990). Other cases which have applied this approach are Asainar bin Sainudin \& Anor v. Mohamad Salam bin Sidik (2002); Mohd 
Yusof bin Abdul Ghani v. Tee Song Kee \& Anor (1995); Muhammad Milshaddiq bin Juri v. Rahmat bin Jamil (1993); Swee Boon King v. Thong Tin Sing \& Anor (1994) and Chandran v. Mohammad Razali bin Jaafar (1992);

(b) Applying a direct multiplier not limited to 16 years. Some cases that have adopted this approach are Zamri Md Som \& Anor v. Nurul Fitriyaton Idawiyah Nahrawi (2002); Wong Li Fatt William (an infant) v. Haidawati bte Bolhen \& Anor (1994);

(c) By taking the life expectancy minus age at the time of the accident and using a direct multiplier. The cases that have adopted this approach are Tan Ah Kan v. The Government of Malaysia (1997); Ng Chun Loi v. Hadzir \& Ors (1993);

(d) By taking the life expectancy minus age at the time of the accident less onethird for contingencies and using the direct multiplier. The cases that have adopted this approach are Chandra Sekaran a/I Krishnan Nair \& Anor v. Ayub bin Mohamed \& Anor (1994); Zainab bte Ahmad v. Keretapi Tanah Melayu Bhd (2000); Nazori bin Teh \& Anor v. Teh Lye Seng \& Anor (1995);

(e) By taking life expectancy minus age at the time of the accident and using annuity tables with no deduction for contingencies. Cases that have adopted this approach are Yu Mea Lian \& Anor v. Government of Terengganu \& Ors (1997); Inderjeet Singh v. Mazlan bin Jasman (1995).

All these approaches are valid under the law and have been endorsed by the superior Courts. Clement Skinner J. in Bujang Mat \& Anor v. Lai Tzen Hai \& Anor (2004) has acknowledged and endorsed all these approaches in determining the multiplier in the assessment of the cost of permanent future nursing care.

However, even after acknowledging and endorsing all these approaches, the Court in Bujang Mat only applied a single approach, i.e. approach (d) above, by taking the life expectancy minus age at the time of the accident less one-third for contingencies and using the direct multiplier. The Court did not indulge itself to specify whether this approach is the valid approach compared to the other. In fact, the Court iterates that any of the approach may be used to determine the multiplier in the assessment of permanent future nursing care/medical expenses.

There are other current authorities which were also inclined to adopt approach (d) in assessing costs for nursing care based on the lifespan approach, i.e. by calculating life expectancy minus age at the time of the accident (after deducting $1 / 3$ for contingencies) and using a direct multiplier. More recent cases which have adopted this approach are Dass Darmalingam v Mohd Fauzi Mohd Salleh \& Anor (2008), Keh Yong Siang \& 5 Ors v Oh Chit Yit \& Anor (Ng Chee Kian - Third Party) (2012) and Muhamad Sukri Jaapar v Mohmad Yusri Ahmad \& Anor (2014). However, the other approaches should not be ignored when each approach appears, for the time being, to be valid methods in assessing permanent future nursing care/medical expenses. 
With due respect, the Court in Bujang Mat should have taken the opportunity to adopt the best-reasoned approach on the issue once and for all when it realised the ambiguity of having a multitude of approaches in calculating permanent future nursing care/medical expenses.

\section{Diversity of Methods}

The existence of diverse approaches to calculating the multiplier in permanent future nursing care is not an anomaly which could remain viable to be left on its own. It is not plausible to have a divergent of calculation, which results in contrasting outcome. Each of the approaches produces different results.

Let us analyse a hypothetical circumstance using the factual circumstances given earlier in the case of John s/o Netchumayah; the Plaintiff is aged 30 years at the time of the accident and with the costs of nursing care at RM 200 a month for the whole life expectancy. For purposes of this analysis, the life expectancy would be based on the expected life span of a male in Malaysia at 75 years age (Department of Statistics Malaysia, 2018).

Applying approach (a), permanent future nursing care would be RM 38,400 (RM 200 $x 16$ years). Approach (b) is much more based on the discretion of the Judge. The Court in Wong Li Fatt William (an infant) applied 10 years' purchase as there was evidence of reduced life expectancy whereas, in Zamri Md Som, 20 years multiplier was applied for a 10 years old claimant. Therefore, for mere analysis, a 20-years' purchase is considered amounting to RM 48,000 (RM $200 \times 20$ years). Approach (c) is simple enough by deducting 30 years from the life expectancy of 75 years, leaving 45 years' purchase, amounting to RM 108,000 (RM $200 \times 45$ years) by the direct multiplier. Using approach (d); taking off from approach (c), the balance 45 years' purchase is further deducted by $1 / 3$ for contingencies, leaving 30 years' purchase amounting RM 72,000 (RM $200 \times 30$ years). Lastly, approach (e) is by calculating the remaining life expectancy via annuity table. This annuity table is based on income at $5 \%$ interests on the capital (Dass, 1975). The result amounts to RM $42,657.77$ based on annuity table for a RM 200 per month multiplicand with a 45 years' purchase multiplier. Thus, using all the 5 approaches above, the outcome diversely ranges from RM 38,400 to RM 108,000.

The simple analysis above reveals different results to the same factual situation. Each approach results in contrasting monetary sum. What separates a case with the other or a claimant with the other for a particular approach to be applied than the other? What consideration entitles the claimant or the court to adopt one particular approach to the other? For the time being, it appears that there are no condition attaches to any of the approaches despite the anomaly of the outcome, as depicted above.

It is not plausible to have a particular set of criteria or consideration to entitle the claimant to apply a specific approach (most probably which earns the highest output), in the calculation of the multiplier for permanent future nursing care since each approach has a different outcome. This would affect the credibility of the judgment; 
if the same case is presented before a different court, it can produce a different outcome. This credibility of judgment is not caused by an error of judgement but is actually endorsed by precedents. Thus, there is a need to correct this "injustices" either by an intervention of legislation or any other methodology to ensure fair and consistent compensation.

In all fairness and in line with the principles of restitution in integrum, permanent future nursing care costs would typically have to be calculated or assessed based on the principle of "life expectancy" of the claimant. The questions of how long the claimant's lifespan would be; whether there is a real prospect of a reduction of the lifespan and inflation or deflation factors, should form part of the issues in the assessment of the damages. The table of life expectancy is used as a general guide to assist in calculating and assessing the number of years needed for future permanent nursing care.

There exists no strict rule or guide as to the number of years nursing care can be awarded. Upon perusal of the trend of awards by the courts, as highlighted above, it is quite clear that there are various methods available. The question follows whether it should remain that way or is it high time to regulate the assessment of permanent future nursing care, as in the assessment of loss of earnings, loss of dependency and bereavement which are regulated in section 7 and 28A of the Civil Law Act, 1956.

\section{The Fallacy of the Approaches}

The Courts had been using the annuity tables approach, which was adopted from the Indian Courts precedents (Dass, 1975). However, the Supreme Court in Marappan \& Anor v. Siti Rahmah bte Ibrahim (1990) stated that the usage of the annuity tables in this country was more a matter of practice than of law when it adopted the direct multiplier approach.

The argument of counsel that the trial judge erred in holding that direct multiplier under section 28A of the Civil Law Act, 1956 should apply to the case, was not adequately deliberated upon by both the trial court and the appellate court resulting in ambiguity of the application of section 28A of the Civil Law Act, 1956 to damages in respect of permanent future nursing care. While the Supreme Court affirmed the existence of the approach of annuity tables in calculating future loss, it did not evaluate whether that approach is still valid or otherwise akin to damages in respect of future loss of earnings and loss of dependency. Furthermore, the provision is specifically for loss of future earnings and should not apply to other types of losses unless the legislators have intended otherwise by properly wording it as such. Thus, with due respect, the application of section 28A of the Civil Law Act, 1956 to permanent future nursing care damages is not within the scope it entails. This Supreme Court's precedent of 1990 in Marappan has been deviated numerous times in the past two decades as highlighted in Bujang Mat, which created more apparent uncertainties. 
The practice of using annuity tables in the assessment of future loss existed even before the amendment to the Civil Law Act in 1984 and was not "repealed" by the amendment made to loss of future earnings, loss of dependency and bereavement. For instance, in the cases of Lai Wee Lian v. Singapore Bus Services (1984) and Murtadza Bin Mohamed Hassan v. Chong Swee Pin (1980), the Courts have used the annuity table, and the issue of double discounting in the form of contingencies and advance payment was very apparent. One of the arguments against the application of annuity tables is that it may be contrary to law when there is no statutory allowance for such application; to the objections of courts that such application was based on practice rather than codified law, as mentioned in Lai Wee Lian, Murtadza and Marappan.

The direct multiplier approach in Marappan suggests that all aspects of vicissitudes of life may have been computed in that statutory provision by the legislative when making the amendment to the Civil Law Act in 1984. Abdul Wahab J. in Asainar had also equated the lump sum payment based on direct multiplier approach under section $28 \mathrm{~A}$ as capital sum akin to calculating future loss based on actual tables or structured payments, as all the contingencies have been taken into account in that approach. After all, the amendment to the Civil Law Act was due to the uncertainty in assessing the loss of future earnings and future loss of dependency before. Section 28A Civil Law Act, 1956 now lays down the "formula" that should be used in such computation of damages. A human being is limited by its mortal abilities and could not precisely compute the exact sum of future losses with all the various considerations and contingencies to be taken into account. Legislative intervention may pave the way for a standard to be practised rather than having discretion applied disparagingly to create more ambiguity. However, that legislative "formula" is simply an arbitrary process in dictating a specific multiplier based on the range of age of the claimant. For instance, claimants who are under 30 years are awarded 16 years multiplier while those who are between 30 to 60 years are awarded multiplier based on the computation of 60 minus the claimant's age at the time of the accident and divide with 2 (Civil Law Act, 1956). There are no actuarial computations or scientific evidence in support of that legislative arbitrary process to predict and assess the multiplier for the permanent future loss.

The direct multiplier approach lessens the hassle of the quantifier or misdirection of the judge on the calculation as the issues of lifespan, reduction of lifespan and contingencies becomes insignificant or academic. A guided outcome of determining the multiplier may be the easiest way to achieve a standard result. The task remains only to find the appropriate multiplicand depending on the factual evidence at hand.

The assessment of nursing care should be included under the Act similar to section 28A Civil Law Act, 1956 rather than applying or sharing a provision which was never initially meant for it. In Wong Li Fatt William (an infant), it was correctly highlighted by Richard Malanjum J. when he said: - 
"In Marappan's case, the multiplier was fixed at 16 on a sum of RM350 per month for the cost of future care. The multiplier of 16 as given under $\mathrm{s}$ 28A(2)(d)(i) of the Civil Law Act 1956 appeared to have been relied upon although the issue was on the cost of future care. I note that the subsection only deals with the loss of 'future earnings' (p.513)."

Thus, direct multiplier by using section 28A of the Civil Law Act, 1956 is not legally proper when that provision is meant explicitly for future loss of earnings and not for other kinds of permanent future loss. However, to allow the issue of the multiplier to be at the discretion of the quantifier or the judge is also not the best option. Perhaps at the least, if the computation of multiplier is certain, the appellate court will not be burdened to determine whether the exercise of judicial discretion by the trial judge was in error.

The approach of life expectancy may be commendable as it strives to accommodate as closest as possible to the principle of resitutio in integrum. However, in practice, to determine the lifespan of the claimant or any reduction of the lifespan in relation thereto are always an issue. The life expectancy has increased through the years, and it appears that the statistical analysis of parties may not be identical between one statistical report to the other; what more the opinions of medical specialists. What consideration or qualification for a judge trained in the words of law has in choosing either parties' propositions or expert opinions? This again leads to unnecessary hurdle and uncertainty in the assessment of such loss.

Deduction of $1 / 3$ for contingencies seems to be another prescription which has no basis. A mere human being, i.e. the judge could not foresee whether or not such contingencies would occur and whether it reduces or escalates the claim, especially when lump-sum payment of damages is adopted. The discount amount of $1 / 3$ of the total damage is also oblivious of its real origin and unsupported by any actuarial computation or scientific evidence and merely depended on past precedents. However, Dass (1975) mentioned that this discriminatory discount factor of $1 / 3$ reduction might have its genesis from the Indian courts, though the Indian judges have not supported that reduction with any actuarial or scientific computation. Such deduction also seems to endorse double discount for a tortuous claim as apparent in Lai Wee Lian and Murtadza.

While the use of annuity table, which was adopted from the Indian Courts practice, maybe age-old practice but it may have served its purpose. The Annuity Table was referred to in the judgment of the Privy Council in Lai Wee Lian. The purpose of setting up an annuity is to show what is the lump sum given the number of years and the annual loss of earnings, and assuming the lump sum will be invested at $5 \%$ profit (which has no basis in the current economic climate), will enable the claimant to replace the annual loss of earnings each year, while drawing upon interest and capital on a declining balance basis until the entire sum is exhausted at the point when earnings would have ceased, had the claimant not been injured (Rutter, 1988). It is to serve 2 objectives: (a) to yield interest on a capital investment basis and (b) to diminish 
the capital sum gradually by withdrawals (Dass, 1975). However, application of annuity table has not reduced the complexity of the computation since it still requires deliberation and assessment of the individual's lifespan, any reduction to that lifespan and the actual numerical figure for the years' purchase and whether any contingency to be further taken into account or not.

It is submitted that the use of the annuity tables to calculate loss of future earnings is not authorised by law and was objectionable in principle. Alternatively, if the tables are used, they must not be used by the direct application of precedents as to the appropriate multiplier. However, the Privy Council in Lai Wee Lian was of the opinion that there is nothing contrary to law or improper about the mere use of the tables, provided that their true effect is appreciated and that they are correctly used. The tables are simply arithmetical tables showing results of certain laborious calculations, always on the assumption that a sum, whether received in damages or in any other way, is invested at $5 \%$ interest. The calculations are not correctly described as "actuarial" as they involve no element of judgment, actuarial or other, except the arbitrary choice of $5 \%$ as the assumed rate of interest.

The danger of using the tables is that the user may not appreciate that the multiplier chosen for use with the tables cannot be directly compared with the multiplier directly applied. A striking example of the kind of error which is likely to occur if the tables are used without appreciating the difference between them and the direct application system is found in Lai Chi Kay \& Ors v. Lee Kuo Shin (1981). In that case also, the Court has made a substantial discount because of the accelerated payment, some reduction for the contingency that the claimant will not reach the average age and some reduction to allow for other contingencies before finding that the appropriate multiplier to be 15 years. How the Court finds this multiplier as appropriate remains oblivious as it was not supported by any scientific credentials.

The estimate of damages for the future cost of nursing care must proceed on the basis that resort will be had to capital as well as income to meet the expenditure. The approach should be therefore, in the first place to assess damages without regard to the risk of future inflation. If it can be demonstrated that on the particular facts of a case, such an assessment would not result in a fair compensation (bearing in mind the investment opportunity that a lump sum offers), some increase is permissible. But the victim of tort who receives a lump sum award is entitled to no better protection against inflation than others who have to rely on capital for their future support. Lord Scarman in Lim Poh Choo v. Camden and Islington Area Health Authority (1979) had said that in order to attempt such protection, it would be to put them into a privileged position at the expense of the tortfeasor, and so to impose on him an excessive burden, which might go far beyond compensation for loss.

\section{Conclusion}

Exclusion of future permanent nursing care or other future losses from the ride in the amendments made to the Civil Law Act, 1956 in 1984 amendment as well again in 
2019 amendment, has left the assessment of that type of future loss to remain in ambiguity with multitude of computation, which seemingly obtains the endorsement of the courts. The case of Marappan being a Supreme Court case may have laid a foundation for a stricter guideline on the computation of the multiplier in this circumstance based on the doctrine of binding precedent. Though many authorities seem to deviate from the precedent, it should remain binding for all courts below. However, it is proposed that permanent future nursing care or permanent future medical expenses and the calculation thereof would be timely included in the statutory provision, as an independent section, similar to section 7 and section $28 \mathrm{~A}(2)$ (d) of the Civil Law Act, 1956, rather than mere back riding a provision which is not supposed to be applicable. Unfortunately, it is still left out in the recent amendment to the Civil Law Act, 1956 vide the Civil Law (Amendment) Act, 2019, which was gazetted on 31 May 2019. Nonetheless, the direct multiplier approach is not the best approach to calculate permanent future loss as it uses a legislative arbitrary process to dictate the number of the multiplier, which is devoid of actuarial calculations and scientific evidence to support such "prediction" of the multiplier for the future loss. Thus, even is legislation intervention is needed in order to standardise the computation of the multiplier, a reliable method for the computation of that multiplier needs to be determined rather than having a simple legislative arbitrary dictation of the multiplier figure as in the current section $28 \mathrm{~A}$ of the Civil Law Act, 1956.

This paper has highlight one of the deficiencies of the law in respect of computing permanent future losses which are not covered under the Civil Law Act 1956, such as permanent future nursing care or permanent future medical expenses. There is indeed a fallacy that the law is consistent in treating like cases with like outcomes for these types of losses. The question follows as to whether to maintain the status quo of adopting various methodology which results in different outcome or is it time to seek a more consistent outcome for the like cases. However, to maintain the current scenario would create more heated debate on the appropriate assessment to be applied. If left at this pace, the computation of damages, especially in the arena of multiplier for permanent future loss in respect of medical treatment and nursing care, would be left at the whims and fancies of the presiding judges without real certainty whether that computation is right or wrong. A solution maybe in the form of Ogden's Tables as practised in the UK could provide an appropriate mechanism for computing future loss; though further study especially in the field of actuarial needs to be conducted on national level and not simply adopting the computation in the Ogden's Tables which is tailored specific to that particular jurisdiction.

\section{References}

Books

Ahangar, M. A. H. (2009). Damages Under Malaysian Tort Law - Cases and Commentaries. Malaysia: Sweet \& Maxwell Asia.

Cane, P. (2013). Atiyah's Accidents, Compensation and the Law (8th edn.). Cambridge University Press.

Dass, K. S. (1975). Quantum in Accident Cases. Malaysia: Malaysian Law Publishers. 
Rutter, M. F. (1988). Handbook on Damages for Personal Injuries and Death in Singapore and Malaysia (1st edn). Singapore: Malayan Law Journal.

Reports Department of Statistics Malaysia. (2018). Abridged Life Tables, Malaysia, 2016 - 2018. Malaysia.

\section{Statutes}

Civil Law Act, 1956.

Civil Law (Amendment) Act, 2019.

\section{Cases}

Asainar bin Sainudin \& Anor v. Mohamad Salam bin Sidik, [2002] 5 ML 104.

Bujang Mat \& Anor v. Lai Tzen Hai \& Anor, [2004] 4 CLJ 127, p. 144-145. [2004] 6 ML 376; [2004] 5 AMR 181; [2004] 1 MLRH 404.

Chandra Sekaran a/l Krishnan Nair \& Anor v. Ayub bin Mohamed \& Anor, [1994] MLU 82.

Chandran v. Mohammad Razali bin Jaafar, [1992] MD 911.

Dass Darmalingam v. Mohd Fauzi Mohd Salleh \& Anor, [2008] 8 MLRH.

Inderjeet Singh v. Mazlan bin Jasman, [1995] 2 ML 646.

John s/o Netchumayah v. Marimuthu a/l Govindan, (1985) Kuala Lumpur HC No. P804/1983.

Keh Yong Siang \& 5 Ors v. Oh Chit Yit \& Anor (Ng Chee Kian - Third Party), [2012] 2 PIR 7.

Lai Chi Kay \& Ors v. Lee Kuo Shin, [1981] 2 ML 67.

Lai Wee Lian v. Singapore Bus Services, [1984] 1 MLJ 325; [1984] 3 WLR 63.

Lim Poh Choo v. Camden and Islington Area Health Authority, [1979] 2 All ER 910.

Marappan \& Anor v. Siti Rahmah bte Ibrahim, [1990] 1 ML 99; [1990] 1 CL 32.

McConnel v. Wright, [1903] 1 Ch 546.

Mohd Yusof bin Abdul Ghani v. Tee Song Kee \& Anor, [1995] MLJU 344.

Muhamad Sukri Jaapar v. Mohmad Yusri Ahmad \& Anor, [2014] MLRHU.

Muhammad Milshaddiq bin Juri v. Rahmat bin Jamil, [1993] MLJU 418.

Murtadza Bin Mohamed Hassan v. Chong Swee Pin, [1980] 1 ML 216.

Nazori bin Teh \& Anor v. Teh Lye Seng \& Anor, [1995] 3 MLRH 235; [1997] 1 AMR 706. Ng Chun Loi v. Hadzir \& Ors, [1993] 1 CL 323.

Swee Boon King v. Thong Tin Sing \& Anor, [1994] MD 1224.

Tan Ah Kan v. The Government of Malaysia, [1997] 2 AMR 1382.

Wong Li Fatt William (an infant) v. Haidawati bte Bolhen \& Anor, [1994] 2 ML 497.

Yu Mea Lian \& Anor v. Government of Terengganu \& Ors, [1997] MLJU 252.

Zainab bte Ahmad v. Keretapi Tanah Melayu Bhd, [2000] 5 ML 620.

Zamri Md Som \& Anor v. Nurul Fitriyaton Idawiyah Nahrawi, [2002] 1 CL 309. 